\title{
Institute for Community Leadership Case Study: Grassroots Authentic Leader Development Program
}

\author{
Willis M. Watt, Ph.D. \\ Communication Department \\ Methodist University \\ Fayetteville, North Carolina 28311 \\ United States of America
}

\begin{abstract}
Since 2004 the Institute for Community Leadership (ICL) program has empowered grassroots community members to step up to the challenge of leading in today's turbulent times. This article presents a case study of the ICL leadership development program for adult learners seeking to serve their community as authentic servant-oriented leaders. To appreciate what ICL has accomplished during its 15-plus years, it is necessary to review the theoretical bases of leadership development, ICL's historical background, its purposes and goals, current activities, past achievements, outcomes and observations, and discussion and conclusions.
\end{abstract}

Keywords: Authentic Leadership; Grassroots Leadership; Servant-Oriented Leadership; Leadership Development; Transformational Leadership; Leadership Training; Civic Leadership

In this first quarter of the $21^{\text {st }}$ century the world is a complex, turbulent place. Our survival is now more than ever before dependent on people who are knowledgeable and skilled leaders. We need effective authentic leaders capable of turning utter chaos into safe communities for all of us to live and work in harmony and peace. We need servantoriented leaders who possess an effective set of principles and skills to practice in every situation during these difficult times. Where do we find this type of leader?

For more than 20 years leadership development programs have become common in the United States (IQ Report, 2001, August). Many of these programs focus on citizens where the outcome is a corps of competent authentic servantoriented grassroots leaders. In these programs participants experience training in a variety of multifaceted learning environments. These programs have shown the potential to empower local grassroots citizens with an opportunity to assume civic leadership roles within their communities. Today's leadership must continue to design and create developmental programs that identify grassroots individuals to prepare them to be effective authentic servant-oriented leaders now and in the future.

\section{Leadership Training versus Leadership Development}

Before we examine the particulars concerning the Institute for Community Leadership (ICL) program, it is helpful to compare leadership training versus leadership development. Based on his experiences with leadership training in corporations, Myatt (2012) suggested most leadership training and development programs do not "come close to accomplishing what they were designed to do - build better leaders" (n. p.). He reported that according to the American Society of Training and Development, in the past businesses in the United States have spent more than $\$ 170$ billion on leadership development. Myatt contended the training industry has been ineffective. Why? Myatt (2012) argued training is the number one reason leadership development fails. He noted that the terms training and development have become synonymous to many people when, in fact, they are not the same thing. Further, he stated that this is more than mere semantics. The problem is training has been merely indoctrination related to"systems, processes and techniques" (n. p.).Trainers have assumed these systems, processes, and techniques are the correct way to lead. He said training focuses on best practices based on "rote, one directional, one dimensional, one size fits all, authoritarian processes that imposes static, outdated information on people" (n. p.). Myatt indicated leadership development must be more than merely a program of training which is primarily monological (e.g., lecture) occurring within a vacuum without a community leadership context.

\section{Leadership Literature Review}

In his seminal work, Servant Leadership: A Journey into the Nature of Legitimate Power and Greatness, Greenleaf (1977) initiated a discussion about two seemingly contradictory concepts - servant and leader. He asked, "Can these two roles be fused in one real person" (p. 7)? 
Greenleaf advocated that individuals can be productive while serving and leading others. He claimed great leaders are first recognized as those who are servants - that is, they seek the welfare and betterment of those around them. In fact, he asserted people will follow only "individuals who are chosen as leaders because they are proven and trusted as servants" (p. 10). Greenleaf suggested in the future viable institutions would be those that are servant led. Therefore, he argued more "servants" need to emerge as leaders in the future. Is this possible? He indicated, it "depends on what kind of leaders emerge and how they - we - respond to them" (p.10). Greenleaf concluded that "among the legions of deprived and unsophisticated people are many true servants who will lead" in the future (p. 14).

But, you ask, where are the legions Greenleaf spoke of? In her chapter, "Leading from the Grass Roots," in The Leader of the Future, edited by Hesselbein, Goldsmith, and Beckhard (1996), Helgesen noted the strength of an organization is in its ability to recognize and value the non-positional power of its members. This non-positional power is vested in the grassroots leaders. She acknowledged that "perhaps the notion of grass-roots leadership strikes us as too much of an oxymoron" (p. 22) because typically we find organizations with a few people in powerful positions who control the resources needed by the majority to accomplish the goals and mission of the organization. According to Helegsen, leadership based solely on positional power fails to take advantage of individuals with expertise, specialized knowledge or skills, personal relational connections, and personal charisma. She claimed the effective organization is one that will "enable people at the grass roots to organize themselves" (p. 22). When those in non-positional power positions are allowed to step up to accept the challenge to lead at whatever level they hold in the organization, then they can lead in place to promote success in achieving the mission and goals of the organization for the benefit of everyone.

George (2003) contended leadership is not about style, but about being authentic. His model of authentic leadership reflected five aspects of what constitutes effective transformational leadership. George indicated such leaders (a) have a strong sense of purpose, (b) hold strong values about what is the right thing to do, (c) establish trusting relationships, (d) demonstrate self-discipline in acting on their values, and (e) are sensitive and empathic concerning the conditions others find themselves in.

According to Hunter (2004), "One need not have positional power in order to positively influence others" (p. 38). He contended "leadership is not synonymous with management. Leadership is synonymous with influence" (p. 46). Hunter claimed leadership is nothing more or less than influencing people to become the best they are capable of and to support the accomplishment of the mission of the organization. For that to happen, he acknowledged the need "to create an environment in which people were supported and encouraged to grow and develop as leaders" (p. 168). In short, Hunter supported the belief that it is important for people to be given the opportunity to step up, to accept the challenge of leading.

According to Crawford, Brungardt, and Maughan (2005), "Social change leadership argues that individuals must ask themselves and others to believe in something larger than personal self-interest as they become active players in the leadership process" (p. 113). They indicated effective leadership development focuses "on the concepts of change, collaboration, and civic responsibility" (p. 111). Crawford et al. suggested developmental programs must be designed to bring about societal change based on the conviction of the importance of these elements, especially the concept of civic responsibility.

Unfortunately, "for many years, the success of one's climb up the corporate ladder was defined by having a seat at the table [only to be] disillusioned by learning that a seat was actually all it was - observer status without a voice" (Carucci, 2006, p. 84). During the past 40 years the importance of empowerment has been a recognized need in organizations, that is, engaging empowered followers to work together to achieve the goals and mission of their organizations. It is difficult to find the right balance; however, positional leaders need to recognize the importance of seeking to liberate the members of their organizations through "information sharing, redrawing boundaries, and replacing hierarchy with teams" (p. 85) as well as other power-sharing tactics. Empowerment (i.e., power-sharing) is founded on trust. Stephen M. R. Covey (2006) posited, "People want to be trusted. They respond to trust" (p. 29). His point was that trust cannot be a manipulative tactic, but if it is genuinely extended to others, it is "the most effective way of relating to and working with others, and the most effective way of getting results" (p. 29).

Examples of leaders and followers trusting each other is explicated in Leading in Place: How Academic Professionals Can Find Their Leadership Voice (Wergin, 2007).Through chapters written by various academic leaders who have taken the leadership challenge, this book provides a glimpse of grassroots leaders stepping up to lead in place. In the chapter titled, "Leadership is Action: Learning to Lead in Place," Watt (2007) stated, "It is apparent to me that if goals are to be met and missions accomplished then engaged leadership is imperative" (p. 179). 
He indicated these imperative calls dem and that the right person, with the right skills and knowledge, with the right expertise, with the right resources, at the right time to step to lead when the need arises in the organization. Maxwell (2007), in part, affirmed this point, in The 21 Irrefutable Laws of Leadership: Follow Them and People Will Follow You. He indicated "good leaders recognize that when to lead is as important as what to do and where to go" (p. 236).

Barrett (2008) indicated individuals are recognized as credible leaders when "they are trusted because of their reputation, because they are good at what they do, because of their knowledge, because they appear confident, and because they are believed to be ethical" (p. 13). When putting the right people, at the right time, in the right place in positions of leadership, it is important to identify individuals who hold to the "shared values and beliefs" of the organization.

Sashkin (2012) disputed this idea of shared. He argued "cultural strength alone, the degree to which members of the organization share a common set of values and beliefs, is a poor predictor of organizational effectiveness" (p.14). Sashkin contended effective organizations are the result of leaders who establish a strong organizational culture with "specific [emphasis added] value and beliefs that culture is built on" (p.15). To accomplish this, he suggested leaders must first define and inculcate appropriate values and beliefs through the use of a clearly defined and articulated "value-based philosophy" (p. 15). The leaders must "empower others to define organizational policies and develop programs based on the values and beliefs contained in the philosophy" (p. 15). And, leaders must "inculcate values and beliefs through their own individual behaviors, their personal practices" (p. 15). With this clarification in mind, it is still important to put theright people, at the right time, in the right place in positions of leadership (Watt et al., 2011).

Most people came to their understanding of leadership from diverse experiences, perspectives, disciplines, and cultures. So, it is a challenge to identify specifically what constitutes effective leadership. The Center for Creative Leadership website (2015) indicated effective leaders must manage people and processes up and down the organizational hierarchy while getting everyone to work collaboratively. Further, authentic leaders must be able to prioritize the complexities of environmental uncertainty, solve multi-dimensional problems, and deal with interconnected systems. The website affirmed the point that leadership is complex stating, "Mid- to senior-level managers — leaders of managers — often say their job is complicated. Exciting and interesting, yes, but definitely not simple" (n. p.). This complexity is because of the many varied traditions, experiences, and ways of thinking about what constitutes leadership.

According to Taylor (2014), "In every change process, there are a variety of stakeholders" (p. 142).It is important that all "ethical and moral leaders strive to treat fairly all interested parties affected by their decisions" (DuBrin, 2016, p. 181). He noted "respecting individuals is a principle of ethical and moral leadership that incorporates other aspects of morality" (p. 282) such as honesty, truth-telling, keeping one's word, and showing respect. Further, he indicated authentic leaders behave in such ways as to promote the welfare of others over their personal welfare. Taylor (2014) indicated that regardless of the specifics of what is being done, a leader's work is not done in isolation - it is not a solitary journey. Authentic servant-oriented leaders must engage other people to accomplish the organization's mission and goals. Lerario (2017) stated, "Inclusive tendencies bring all other participants and information into the execution of leadership duties and tasks" (p. 24). The goal is collaboration. Working with a variety of stakeholders as they move through changing environments, authentic servant-oriented leaders will find that the path to success requires a clear buy-in by everyone (Carucci, 2006; DuBrin, 2016; Lerario, 2017;Sashkin, 2012; Taylor, 2014).

Authentic servant-oriented leaders are "people who have cultivated humility and made it an important part of their lives" (Davis, 2017, p. 209). He pointed out that humility has the power to positively affect nearly every aspect of a leader's personality. As he noted, leaders who have cultivated humility have more energy to devote to others. Davis has clearly defined the value and essence of humility - "Humility allows us to strip away our ego, to suppress the need to be visibly right at every turn, and to take the longer view" (p. 213). Rather than being consumed with self and selfwants, the authentic servant-oriented leader is able to contribute to and help others as they work together to accomplish organizational goals and missions.

Leadership should not be reserved only for the elite upper echelons in government, businesses, and public and private organizations (Hartzog, 2018). "The mastery of leadership remains in the sphere of daily life, and it is available to anyone who employs the proper balance of three simple concepts: Authority, Ability, and Character" (p. 7).He concluded these three aspects represent authentic leaders who serve from the "simplest to the very highest levels" (p.212). Hartzog defined authority as the traits and attributes defining the power to influence others. As for ability, he indicated it refers to skills that a person possesses. And, he noted that character involves a combination of integrity, honesty, humor, empathy, and caring for others that goes beyond simple charisma. 
In support of the grassroots concept, Hackman and Johnson (2018) indicated people find most beneficial situations where they experience being in a leader role. Effective leadership development programs works best when learnerparticipants are given the opportunity use what they learn in private and public settings. This approach is founded on the belief that leadership is not the sole prerogative of the rich and famous, or the powerful in their communities (Maxwell, 2018).

According to Northouse (2019), "Authentic leadership can be differentiated into two areas: (1) the practical approach and (2) the theoretical approach" (p. 198). In his explanation of practical authentic leadership, he elaborated the five aspects of George's (2003) Authentic Leadership Model. Northouse (2019) stated that having a sense of purpose meant leaders "are passionate individuals who have a deep-seated interest in what they are doing and truly care about their work" (p. 199). He noted authentic leaders hold to stated values "when tested in difficult situations...they do not compromise their values" (p. 200). He pointed out authentic leaders "has the capacity to open themselves up and establish a connection with others" (p. 200). According to Northouse, self-discipline is "a quality that helps leaders reach their goals" (p.201). Further, he suggested authentic leaders display compassion by "being sensitive to the plight of others, opening one's self to others, and being willing to help them" (p. 201).

\section{The Institute for Community Leadership (ICL)}

The leaders engaged in the work of the Institute for Community Leadership recognize that connecting theory to practice is complicated, but as Kouzes and Posner (2017) rightly asserted leadership can be learned. To be an authentic servant-oriented leader, it is essential for people to rise to meet the leadership challenge. After all, everyone can make a difference in the organization where they work and serve.

According to Watt et al. (2011), there is no one best way to be an effective leader. It is, therefore, incumbent upon us to prepare people to be effective authentic leaders. Northouse (2019) noted people "want to know the 'how to' steps to become an authentic leader" (p. 199). The Institute program provides an answer to the question how to be an authentic servant-oriented leader. The Institute intentionally strives to educate and develop participants to be leaders in their community. As a grassroots leadership development program, it is open to all registered voters who are residents of Cumberland County, North Carolina. It is tuition free. The Institute provides practical applications of what is learned, thereby empowering participants to practice authentic servant-oriented leadership.

The importance of grassroots leadership is underscored on the Ben and Jerry's website (2015). The site pointed out that the people most affected by a problem or any situation are those best able to identify how to deal with the situation. According to the website, "Grassroots, constituent-led organizing is among the most effective means to create social change" (n. p. n.). It further suggested lasting change occurs when people act from the ground up as grassroots groups. The site offered a challenge calling for leadership development that prepares grassroots leaders to deal with changing the negative "underlying, systemic forces" (n. p. n.) in this country.

The ICL program can be used as a model for others to create learning and developmental programs for people who have no opportunity or context for leading in their community. With that in mind, we will examine how ICL came to be, what it looks like, past and present activities as well as several learning outcomes occurring in 15-plus years of operation.

\subsection{Historical Background}

As a response to a perceived lack of local leadership opportunities, an initial effort was made to create and develop a citizens' leadership academy. In July 2001 an assistant to the city manager indicated strong support for a substantive, joint City-County leadership development academy. Over the next two years discussions followed among a variety of leaders in the community at large, in higher education, in the city manager's office, and the Chamber of Commerce.

In 2003 several community leaders began the work of developing a grassroots leadership development program. The initial intent was to identify and train citizens for appointment to local boards and commissions to serve as leaders in the community. It was decided graduates could also fill vital leadership roles in churches, for-profit, not-for-profit, and civic organizations. The result was the formation of the Institute for Community Leadership (ICL).

The efforts of the Institute have been recognized for its contributions to the community. Early on, Former Chancellor of Fayetteville State University, Dr. T. J. Bryan, stated ICL reflected the community's steadfast commitment to improving the quality of life for residents. Over the years ICL has been commended for developing and empowering community citizens to serve in a variety of leadership positions. 


\subsection{Organizational Structure}

The Institute is a unique partnership between government, educational institutions of higher education, and private organizations in our community. The Institute sponsors include the City of Fayetteville, Cumberland County, Cumberland County Public Schools, Fayetteville State University, Fayetteville Technical Community College, and Methodist University. The local Arts Council is a non-dues-paying partner supporting the work of ICL. The ICL Board consists of the presidents of the colleges, university chancellor, county school superintendent, county and city managers. They make guiding decisions concerning the ongoing program and provide the fiduciary support for ICL. The Board members identify and provide one or two additional staff members from their organization to do the staff work.

Sponsors provide invaluable resources and assist in the achievement of the vision of ICL. They host the Institute's training events as well as provide trainers and panelists. In addition, they oversee the annual participant nomination and selection process. Essentially what they do is provide leadership oversight and ensure legitimacy to sustain the ICL program.

On a two-year rotation, each of the six sponsoring entities provides a person to serve as the Executive Director. The executive director is responsible for setting the agenda for Board meetings, coordinating and overseeing the training sessions, assisting in the selection and approval of the participants in each cohort, facilitating connections within the ICL Board membership, assisting with ICL advertising though the local news outlets, working with each cohort in the selection of and completion of the class project, helping maintain an alumni group, and providing awards and supporting the graduation ceremonies.

The Institute leadership has identified three other important areas to maintain the ongoing success of its leadership development program. Because each of the sponsors is responsible for financing the work of ICL, a sponsor is designated to provide a treasurer to maintain expenditures and propose an annual budget. Second, a sponsor provides a staff member to oversee and maintain its webpage which can be found at www.leadership4us.org. And, one of the sponsors ensures the continuity of ICL by assigning an historian to oversee the housing and storage of ICL annual reports as well as other important documents.

\subsection{Purposes and Goals}

According to former ICL Executive Director, Dr. Andrew Ziegler, the intent of ICL is to reach people who are not currently involved in the community, but who sincerely desire to serve in some way. As indicated above, ICL is a joint community effort designed to provide local grassroots citizens the opportunity to participate in activities leading to community leadership and membership on boards and commissions as well as work with other private civic and religious entities. From its beginnings through its current efforts, ICL has sought "To identify, develop, and empower community members, especially those not previously identified, who are able and willing to commit to leadership roles in addressing the issues of the Fayetteville/Cumberland County area" (ICL brochure, 2020).

\subsection{Current Activities}

According to current ICL Executive Director, Dr. John W. Edwards II, the opportunity to experience leading an organization, to include planning, coordinating with sixsponsor organizations, making decisions, and solving problems is a challenge for the ICL staff and class participants. The Covid-19 pandemic brought with it unique opportunities for class members together to lead and engage in real-world problem solving. The 2019-2020 class worked as a team to discuss how to complete the final months of the program. Several class members stepped up to take responsibility and offer suggestions to overcome the obstacles the class confronted in the completion of their training and development. The participants used technology to a greater degree than any other class before it in order to complete the program requirements via online discussions, email, Groupme, and others venues. Through their actions the 2019-2020 class was able to stay together and in touch to complete the training program and class project. The Institute is currently training and developing participant leaders in the 2020-2021 Class XVII.

Community members interested in completing the program complete an application form (see www.leadership4us.org).It is important to note that each candidate must demonstrate in a written essay a sincere commitment to serve the community and agree to attend each session of the Institute. Additionally, applicants must indicate a willingness to pursue an appointment to a governmental or community board or commission, or other community leadership role. Applicants are evaluated and selected by a committee of ICL staffers. The prospective 3035 candidates are presented to and voted on by the Board at its annual August meeting. Due to the effects of COVID19, the 2020-2021 class size was limited to 18 participants who meet from September through April. 
The Institute annually hosts seven training sessions focused on leadership development through enhanced training activities, discussions with some of Fayetteville's and Cumberland County's most effective and dynamic leaders, and practical application of leadership theories and techniques through a community project. Topics covered include, but are not limited to, skills training, community issues, and service opportunities on a variety of commissions and voluntary boards. Each session focuses on one area for community involvement including such aspects as arts and culture, city and county government, education, and not-for-profit human services. The monthly sessions are conducted at the host Sponsor location. These locations include City Hall, the county Courthouse, campuses of the three institutions of higher education, and the Arts Council. This feature of ICL brings citizens into places and facilities they may have not experienced, thus broadening their exposure to community life.

Sessions include an introductory meeting, discussion about community issues, and opportunities for service on boards serving various not-for-profit service agencies, city and county government, arts and culture boards, and schools, colleges, and universities. Because participants learn about opportunities for volunteer service, they are better able to decide where their abilities as authentic servant-oriented interests fit best within the community.

The first five training and development sessions focus on establishing relationships, leadership styles, communication, teamwork, along with skills needed by people who serve in leadership roles and positions. Session Six includes an "Opportunity Fair" which is held at the local Arts Council. Over 30 local organizations and agencies participate. Each one has a table with materials and displays to inform and encourage ICL participants to sign up on the spot for volunteer service. Members of the current cohort are required to sign up with at least one of the organizations. This session also involves an alumni meeting and programming to bring together current and past class members. A graduation dinner honoring participants completes the cohort cycle.

Following graduation participants receive mentoring by the staff of the partnering agencies. Mentors assist graduates in the application process for boards and commissions as well as other servant-oriented leadership opportunities where participants can serve their communities in an authentic way. Refer to Table 1 for a breakdown of the ICL annual training program.

\subsection{Past Achievements}

Maxwell (2007) suggested, "At some point we need to end the lecture and send them out to try what they have learned" (p. 1191). To that end, over 400 participants have gone out into the communities in Cumberland County to participate in key community decisions affecting local issues and provide solutions in areas that impact all residents. The ICL graduates have found numerous volunteer leadership positions that best fit their skills, talents, and interests. Table 2 is an overview of some of the many, but not all, areas in which ICL participants are or have served and lead in our communities since its inception with 2004-2005 Class.

As indicated earlier, citizen led efforts serve as spark plugs for growth and development (Ben and Jerry Foundation, 2015; Carucci, 2006; Center for Creative Leadership, 2015; Crawford, et al., 2005;DuBrin,2016; Hunter, 2004). Recognizing the centrality of such efforts to the quality of life in Cumberland County, the sponsors have been willing to step forward and show responsibility for continuing leadership development through ICL. The work of ICL has led to the identification and involvement of numerous individuals who otherwise may not have become active authentic servant-oriented leaders in the community.

The Institute has provided programming designed to develop grassroots leaders in our communities who have been armed with the relational connections, knowledge, skills, and tools needed to be authentic servant-oriented leaders. The developmental work of the Institute has resulted in ever expanding pool citizen leaders who are willing and qualified to serve as authentic servant-oriented leaders in a variety of roles and positions.

To better ensure the success of ICL, the Board has added elements to the overall program. First, in order to know where to go, we need to know where we have come from. So, the ICL leaders have added an alumni unit to ICL. This gives ICL participants an opportunity to interact with and learn from others who have completed the training program.

Also, to know what has been done in the past and who has participated in ICL, the Sponsors added a position of Historian who is responsible for maintaining ICL documents. In an effort to reach out to the community as well as provide a link to the Institute, the ICL leadership established and maintains a website (see www.leadership4us.org). 


\section{Appendices}

\section{Table 1}

\section{ICL Training and Development Sessions}

\begin{tabular}{cll} 
Session Training Topic & Panel Topic & \\
1 & Getting to Know You & Not-for-Profit Services and Organizations \\
2 & Leadership Style & County Boards and Issues \\
3 & Communication & City Boards and Issues \\
4 & Teamwork & Higher Education Boards and Issues \\
5 & Board Member Toolbox & Public Education Issues: Making the Connection \\
6 & Arts and Cultural & Opportunity Fair Organizations \\
7 & Graduation Dinner & Graduation Speaker and Awards \\
\hline
\end{tabular}

\section{Outcomes and Observations}

What has the ICL leadership development program taught us?

Training alone not effective preparing authentic servant-oriented leaders - leaders must be developed (Myatt, 2012).For example, one participant said, "The most important aspect of the program for me was that I connected with people from volunteer organizations that I was able to spend time with after the program was complete."

Public and private organizations need authentic, transformative leadership (George, 2003) consisting of servantoriented leaders (Greenleaf, 1977). According to a former class participant, "My favorite organization is Cumberland County Child Advocacy Center. I spent 4 years actively speaking in the community on their behalf ... I felt good about what I was doing."

Innumerable individuals want to lead (Hartzog, 2018). These people exist at all levels within an organization and they bring value to the organization while serving in non-positional power roles (Helgesen, 1996).

Benefits of longevity of ongoing program. The 15-plus years of developing grassroots authentic servant-oriented leaders in our community speaks positively to the need for the ICL program. Dr. John W. Edwards II is a prime example. He has been associated with ICL for the past 10 years as a Class VII participant, Fayetteville Technical Community College and Methodist University staff trainer, ICL Board member, and the Executive Director by completing a two-year rotation for classes 2019-2020 and 2020-2021.

Affordability key to allow grassroots leadership development. While many training and development programs exist (even in our community), typically such opportunities are expensive, therefore, cost prohibitive to the ordinary person. The ICL program is cost-free to the participants because the six Sponsors fund ICL.

Program growth and expansion. In the first several cohorts participants were primarily individuals living in Fayetteville and were employed by the six Sponsors; however, in the past seven or eight years ICL has seen the cohort pool include individuals from a wide variety of towns and different organizations (see Table 2).

\section{Table 2}

\section{Examples of Service and Leadership Activities Performed by ICL}

\section{Participants}

Adult HomeCare Advisory Board (9)

Airborne Special Operations Museum (5)

Alpha Academy Youth Program

Alpha Kappa Alpha Sorority

American Legion Post 32

American Red Cross (4)

Botanical Gardens Board

Boy Scouts Eagle Mentoring Program (2)

Cadet Corps Youth Mentorship Program (2)

Cape Fear High School Alumni Association

Cape Fear Regional Theater (4) 
Caring 7 Feeding the Homeless Program

Chamber of Commerce Ambassador

Children of Prisoners Program

Christmas Angel Tree Project

Christmas "Bicycle Man" Project

City-County Appearance Commission

City-County Senior Citizen Commission

Community Outreach Assistance Services

Council for Older Adults

Council on Shooting Sports

County Action Program (3)

County Air QualityStakeholders Program

County Arts Council (21)

County Board of Adjustments

County Better Health Board

County Board of Wildlife Club

County Boys \& Girls Club (2)

County Child Advocacy Center (4)

County Community Care Board

County Commissioners

County Disaster Recovery Coalition

County Dispute Resolution Center (2)

County Elections Board

County Emergency Planning Committee

County Fair Committee

County Foundation

County Juvenile Crime Prevention Council

County Legal Aid Center

County Library Commission (4)

County Mental Health Board

County Partnership for Children (2)

County Progressives

County Schools Mentors (8)

County Social Services Department (2)

County Transportation Board

County Workforce Development Board

Crew 32 Committee

Crosse Creek Rifle and Pistol Club

Dogwood Festival Committee (3)

Delta Sigma Theta Sorority

Economic Empower-Develop Program (2)

Exceptional Children's Services

Fascinate U Youth Museum (2)

Fayetteville Area Cultural Foundation

Fayetteville Beautiful Board

Fayetteville City Council

Fayetteville Downtown Alliance Board

Fayetteville Family Life Center

Fayetteville - Gilbert Theater

Fayetteville Homeless Program (3)

Fayetteville Junior League of Leaders

Fayetteville Metropolitan Housing Authority

Fayetteville Observer Credit Union Board

Fayetteville Oprah Book Club

Fayetteville Personnel Review Board (2) 
Fayetteville Planning Commission (2)

Fayetteville Public Works Commission (2)

Fayetteville Recycling Task Force

Fayetteville Redevelopment Commission

Fayetteville Symphony Orchestra (4)

Fort Bragg Unit Scholarship Committee

Friends African-American Art Committee

FSU Upward Bound Program

FTCCSmall Business Center

FTCC Program Coordinator

Fundraiser 100 Black MenScholarship

Great Oaks Youth Development Center (4)

Greater Good Athletic Association

Guardian Ad Litem Program (2)

Habitat for Humanity (5)

Harry Hosier UMC Administrative Council

Head Start Program

Horses That Heal Program

Hope VI Grant Program

Hope for the Homeless Program

International Folk Festival Committee

Magby \& Associates, Inc. Board

Mid-Carolina Council of Governments

Nat'l Assoc. Insurance-Financial Advisors

NC Council of Community Programs

NC Veterans Park Design Committee

Old Wilmington Rd Improvement Program

Operation In-As-Much (2)

Parent-Teacher Association

Salvation Army

Second Harvest Food Bank (4)

Southeastern NC Radio Reading Service (4)

Sustainable Sandhills Organization

Teen Mothers of Preschoolers Program

Terry Sanford H. S. Band Booster Club

Town - Godwin City Commissioner

Town - Hope Mills Youth Assoc. Board

Town - Morrowville Adjustments Board

Town -Wade Commissioner (2)

Town - Wade Fire Department

Town - Wade Appearance Commission (2)

Town - Spring Lake Water Advisory Board

Town - Westover City Theater

United Way of Cumberland County (11)

Urban Ministries (12)

VA Volunteer Services Program

Vision Resource Center (2)

WFSS 91/9 FM Public Radio

NOTE: Numbers in parentheses indicated the number of participants who are or have served in the area of leadership.

Benefit to the community-at-large. The value of broader involvement is evidenced by a participant from the town of Hope Mills who stated, "I learned about the impact of child abuse in our community and I learned what the county is doing to combat the problem. I worked on several fund-raiser projects with CAC." In other words, ICL has become a countywide leadership development program. 
Evaluation and assessment of the training program is critical for success. The Board has tweaked the training program (see Table 1) based on of the participant feedback; however, the program has largely remained the same throughout the ICL history.

Sponsorship commitment invaluable. The six sponsors remain committed to ICL themission through funding, housing, staffing, and providing an executive director.

Relational connections enhance effectiveness of ICL. As a class participant indicated, "I was forced to interact with people in ways that helped me to grow. By nature, I am an introvert so I was "forced" to expend the energy to take charge."

Interaction with established community leaders a major benefit for participants. The experience and wisdom gained goes a long way in helping them identify attitudes, behaviors, and skills they can use in their leadership.

Various Sponsor locations for training. The use of each Sponsor's facilities exposes the participants to areas in the city and county many would not have known about or had access to. This provides a much increased community awareness among the participants.

Hands-on learning experiences. This standard part of the training the participants receive supports the value of experiential learning. The high level of participant interaction during training allows the individuals tocoalesce as a team learning and working together through the sharing of the leadership role (Hartzog, 2018; Lerario, 2017; Taylor, 2014).

Commitment to community project requirement. The community project is evidence of the learning and development participants experience as authentic servant-oriented leaders (Northouse, 2019). Very early in ICL history, without any direction from staffing,a cohort decided to complete a community project. The project morphed into a community project requirement for subsequent cohorts. Among the positives related to the community project concept is that many cohorts go beyond the minimum requirement to complete multiple projects that benefit the community.

Increased interest among county residents. Over the past 15-plus years interest in and involvement among county residents has been grown as they participate in ICL. This growth substantiates the quality and value of ICL for indivudal participants and the communities at large. The initial two cohorts had 20-25 participants; however, since that time the average number has been 60 to 75 applicants for 30 seats in a cohort. What this says about leadership development, in general, and specifically the ICL program is that people want to be involved in leadership (Greenleaf, 1977).

\section{Discussion and Conclusions}

It is the mission of ICL to continue to offer grassroots authentic servant-oriented leadership development to educate and train civic leaders (Crawford, et al.,2005) for membership on private and public boards and commissions as well as other not-for-profit and for profit organizations. In order to achieve its vision and mission, the sponsors remain committed to continued funding, staffing, and provision of an executive director. In its initial year the sponsors of ICL hired an executive director to ensure the program was well established including development of its curriculum, identification of trainers and panelists, selection of participants, advertising, public relations, creation of a brochure, and a website (see www.leadership4us.org). The Sponsors were able to make this hire based on funding from a significant grant from the Cumberland Community Foundation. While the current rotation among the sponsors to provide an executive director for ICL, it would a positive step forward to be able to finance the hire of a permanent executive director.

As the ICL program continues to mature in the future, the Board is working on a more expansive mentoring program for its participants. Part of this mentoring includes working with cohort participants in at least one community service project which they identify the need for, select, organize, and complete for the benefit of the Fayetteville/Cumberland County area.

It is possible ICL collaboration among private and public entities could evolve to include a "community think tank" to create opportunities for those involved in community civic leadership (Center for Creative Leadership, 2015) to come together to learn about and discuss common interests.

The Institute will continue to empower community members for civic leadership positions, thus improving the quality of life in our community. Through several years of providing a grassroots community leadership development program for civic leaders, the efforts of ICL Board confirm Crawford et al.'s (2005) and Ben and Jerry Foundation's (2015) 
claims that leadership development is an essential component of social change in a community. If true social change is to occur, then authentic servant-oriented leaders will need to deal with the underlying, systemic forces which negatively impact our community.

The ICL leadership development program must continue to prepare civic leaders to challenge the status quo, demand policy change, and educate citizens about the root issues and causes of problems affecting their community. These authentic servant-oriented leaders prepared by ICL can be advocates who work for systemic, just solutions that promote positive social change. The Institute is convinced lasting change occurs when Social Justice Movements are built from the ground up and grassroots groups come together across sectors and constituencies to work for the common principles of Human Rights and Justice for All.

The benefits of the ICL program are many. As more and more emergent civic-minded authentic servant-oriented leaders graduate from the program, the community will see increased positive tangible results. The institutions and organizations, both public and private, that the ICL graduates serve will see improvement in solving the issues and problems they face. These empowered leaders are likely to motivate others to achieve great successes in our community. And, with ICL training the participants will be able to change the way traditional leaders and their followers solve public and private problems.

At this time it appears that indeed the Institute for Community Leadership development program has a bright future in Fayetteville, Cumberland County, North Carolina. The Institute will continue to provide leadership development training to empower grassroots community members for authentic servant-oriented leadership for another 15 years.

\section{References}

Barrett, D. J. (2008). Leadership communication (2nd ed.). Boston: McGraw-Hill companies.

Ben and Jerry Foundation (2015). Organizing for social change program. Retrieved from http://benandjerrysfoundation.org/the-grassroots-organizing-for-social-change-program

Carucci, R. A. (2006). Leadership divided: What emerging leaders need and what you might be missing. San Francisco: Jossey-Bass.

Center for Creative Leadership (2015). Leadership programs. Retrieved from http://www.ccl.org/leadership/programs/LDPOverview.aspx

Covey, S. M. R. (2006). The speed of trust: The one thing that changes everything. New York: Free Press.

Crawford, C. B., Brungardt, C. L., \& Maughan, M. R. C. (2005). Understanding leadership: Theories \& concepts (3rd ed.). Danvers, MA: Wiley.

DuBrin, A. J. (2016). Leadership: Research findings, practice, and skills (8th ed.). Boston: Cengage Learning.

George, B. (2003). Authentic leadership: Rediscovering the secrets to creating lasting value. San Francisco: Josey-Bass.

Greenleaf, R. K. (1977). Servant leadership: A journey into the nature of legitimate power and greatness. New York: Paulist Press.

Hackman, M. Z., \& Johnson, C. E. (2018). Leadership: A communication perspective (7thed.). Prospect Heights, IL: Waveland.

Hartzog, A. B. (2018). Three-Dimensional leadership: Abilities, authority, character. Meadvillle, PA: Christian Faith Publishing.

Helgesen, S. (1996). Leading from the grassroots, in The Leader of the Future, Hesselbein, F., Goldsmith, M., \& Bechhard, R. (Eds.). New York: The Drucker Foundation.

Hunter, J. C. (2004). The world's most powerful leadership principle: How to become a servant leader. New York: Crown Business.

ICL (2020). Institute for Community Leadership brochure, P. O. Box 87464, Fayetteville, NC, 28304.

IQ Report (2001, August). Citizen Academies. International City/County Management Association, 307, 8, 115.

Kouzes, J. M., \& Posner, B. Z. (2017). The leadership challenge: How to make extraordinary things happen in organizations (6th ed.). San Francisco: Jossey-Bass.

Lerario, M. (2016). Leadership in balance: The Fulcrum-Centric Plan for emerging and high potential leaders. Hasmark Publishing.

Maxwell, J. C. (2007). The 21 irrefutable laws of leadership: Follow them and people will follow you(10th anniversary ed.). Nashville: Thomas Nelson.

Maxwell, J. C. (2018). Developing the leader within you 2.0. Nashville: Thomas Nelson. 
Maxwell, J. C. (Ed.) (2002). The Maxwell leadership bible (NKJV). Nashville: Thomas Nelson.

Myatt, M. (2012). The 1 reason leadership development fails. Retrieved from

Forbes.com/sites/mikemyatt/2012/12/19/the-1-reason-leadership-development-fails/

Northouse, P. G. (2019). Leadership: Theory and practice(8th ed.). Sage.

Sashkin, M. (2012). Leadership, in Rosenbach, W. E., Taylor, R. L., \& Youndt, M. A. (Eds.), Contemporary issues in leadership(7th ed.). Boulder, CO: Westview Press.

Taylor, K. (2014). The leader's guide to turbulent times: A practical, easy-to-use guide to leading in today's time. Evergreen Leadership.

Thompson, F. M. (2001, July 11). City-County Leadership Development Academyletter. Fayetteville, NC.

Todd, D. (2017). Get better: 15 proven practices to build effective relationships at work. New York: Simon \& Schuster.

Watt, W. M. (2007). Leadership is action: Learning to lead in place, in Leading in Place: How Academic Professionals Can Find Their Leadership Voice, J. F. Wergin, (Ed.). Bolton, MA: Anker Publishing.

Watt, W. M., Ballard, K. E., Inghram, B. D., Purser, R. E., Wayland, J. V., \& Wilson, D. L. (2011 Summer). Contemporary issues in leadership: A field study of leadership development, in International Leadership Journal, 3(2), pp. 109-129. Trenton, NJ: Thomas Edison State College.

Wergin, J. F. (2007). Leading in place: How academic professionals can find their leadership voice. Bolton, MA: Anker Publishing. 